\title{
QUALIDADE SANITÁRIA DE CENOURAS MINIMAMENTE PROCESSADAS E CENOURAS IN NATURA
}

\author{
BELUSSI SILVA, Kerly Francieli ${ }^{1}$ \\ KOZUSNY-ANDREANI, Dora Inés ${ }^{2}$ \\ ANDREANI JUNIOR, Roberto ${ }^{2}$
}

\begin{abstract}
Recebido em: 2018.04 .15
Aprovado em: 2021.02.22

ISSUE DOI: $10.3738 / 1982.2278 .2968$

RESUMO: Objetivou-se nesta pesquisa avaliar a qualidade sanitária de cenouras minimamente processadas e cenouras comercializadas in natura. Nos procedimentos microbiológicos foram avaliados coliformes totais, coliformes termotolerantes e Escherichia coli, pesquisa para Salmonella spp., Foram isolados coliformes totais, coliformes fecais, Escherichia coli em $100 \%$ das amostras de cenouras in natura e em $20 \%$ das cenouras minimamente processadas. A concentração destes micro-organismos variou entre $10^{3}$ e $10^{9} \mathrm{UFC} \mathrm{g}^{-1}$. Salmonella spp foi isoladaem 93,3\% das cenouras in natura. A elevada frequência de micro-organismos patogênicos, nas amostras de cenouras, evidenciou precariedade nas condições higiênico-sanitárias da cadeia de produção, as quais podem conduzir à contaminação e deterioração do alimento, comprometendo a qualidade do mesmo, bem como constituir-se em um risco a saúde pública.
\end{abstract}

Palavras-chave: Daucus carota L, coliformes, Escherichia coli, Salmonella,

\section{SANITARY QUALITY OF MINIMALLY PROCESSED CARROTS AND IN NATURA CARROTS}

SUMMARY: The objective of this research was to evaluate the sanitary quality of minimally processed carrots and carrots commercialized in natura. In the microbiological procedures, total coliforms, fecal coliforms and Escherichia coli and Salmonella spp. Were evaluated total coliforms, fecal coliforms, Escherichia coli were isolated in $100 \%$ of fresh carrot samples and $20 \%$ of minimally processed carrots. The concentration of these microorganisms varied between $10^{3}$ and $10^{9} \mathrm{CFU} \mathrm{g}^{-1}$. Salmonella spp was isolated in $93.3 \%$ of the carrots in natura. The high frequency of pathogenic microorganisms in the carrot samples evidenced precariousness in the hygienic-sanitary conditions of the production chain, which can lead to the contamination and deterioration of the food, compromising the quality of the food, as well as constituting a risk to public health.

Keywords: Daucus carota L, coliforms, Escherichia coli, Salmonella,

\section{INTRODUÇÃO}

As hortaliças apresentam importante papel na alimentação humana, principalmente por serem excelentes fontes de vitaminas, minerais e fibras, também por conter em sua composição diferentes grupos de substâncias químicas que atuam no organismo humano em diferentes funções (ALVES et al., 2010, TEMGOUA et al., 2015; AKOACHERE et al., 2018).

Uma importante hortaliça do grupo de raízes é a cenoura que vem sendo amplamente utilizada na alimentação. Pertence à Família Apiaceae, que produz raízes aromáticas e comestíveis, caracterizando-se como uma das mais importantes olerícolas, em função de seu consumo em todo mundo, pela extensão de área plantada e também pelo envolvimento sócio econômico dos produtores rurais (LIMA et al., 2003).

\footnotetext{
${ }^{1}$ Mestre pela UNESP/Ilha Solteira

${ }^{2}$ Professor (a) Titular do Mestrado em Ciências Ambientais. Universidade Brasil. Fernandópolis-SP
} 
Os hábitos alimentares vêm sofrendo grandes mudanças quanto ao consumo de vegetais frescos. Os consumidores desejam cada vez mais produtos de elevada qualidade e que apresentem facilidades de preparo e utilização. A fim de atender a essa demanda, as indústrias de processamento de alimentos lançaram no mercado frutas e hortaliças manipuladas de tal forma que seus tecidos vivos mantenham as características do produto fresco (AGUILA et al., 2006). Os frutos e as hortaliças minimamente processados caracterizam-se por um preparo mínimo como pesagem, seleção, higienização, descascamento e corte (LIMA et al., 2003).

Um alimento é um recinto ecológico completo e dinâmico composto por muitos microambientes. As etapas de elaboração dos produtos minimamente processados e os próprios processos respiratórios dos vegetais afetam estes microambientes e, consequentemente, o desenvolvimento microbiano (PINHEIRO et al., 2005).

Tradicionalmente, os produtos frescos não eram alvo de muita preocupação por parte de órgãos regulamentadores, pois eram considerados seguros, já que eram lavados e rapidamente consumidos no próprio local de preparo. Devido à elevada manipulação e ao incremento no consumo de minimamente processados, tanto em âmbito doméstico quanto institucional, a preocupação com o risco potencial para a saúde pública aumentou, devido à probabilidade de contaminação microbiológica (SANTOS, 2010; SANTOSA et al., 2012). Considerando os elevados índices de doenças veiculadas por alimentos, provocados por micro-organismos patogênicos que podem estar presentes em qualquer ponto da cadeia produtiva, desde o cultivo, colheita, lavagem, armazenamento, transporte, comercialização e, finalmente, na mesa do consumidor (SANTOS, 2007).

Juntamente com o crescimento do setor de minimamente processados no país, cresce também o relato de doenças infecciosas associadas ao consumo de frutas e hortaliças minimamente processadas, o que tem despertado o interesse de agências regulatórias, como a Agência Nacional de Vigilância Sanitária (ANVISA), e de institutos de defesa dos direitos dos consumidores, como é o caso do Instituto Brasileiro de Defesa do Consumidor (IDEC) (ANDRADE et al., 2004).

A qualidade microbiológica de alimentos minimamente processados está diretamente relacionada com a presença tanto de micro-organismos deterioradores, que causam alterações indesejáveis das características sensoriais do produto e, também, de micro-organismos patogênicos. Assim, a segurança microbiológica diz respeito à ausência de micro-organismos patogênicos causadores de infecção alimentar e de toxinas microbianas responsáveis pela intoxicação por alimentos (SILVA, 2006). 
Os cortes ou danos no tecido da planta, que está sendo processada, favorecem a liberação de nutrientes e enzimas intracelulares que promovem a atividade enzimática e a proliferação de micro-organismos no produto (FANTUZZI et al., 2004). Por tanto, a qualidade e a segurança dos alimentos minimamente processados estão intimamente relacionadas ao método de processamento utilizado, à qualidade da matéria prima, ao o uso de embalagens apropriadas e às condições adequadas de armazenamento (PAULA et al., 2009).

A microbiota presente em vegetais frescos constitui-se basicamente de micro-organismos pertencentes à Família Enterobacteriaceae. Entre os gêneros da Família Enterobacteriaceae, encontra-se a Escherichia, sendo a principal espécie a Escherichia coli, pertencente ao grupo dos coliformes termotolerantes (SILVA et al., 2010; ONUORAH et al., 2016).

A presença de coliformes termotolerantes nos alimentos pode indicar qualidade higiênicosanitária insatisfatória, quer seja pela contaminação da matéria prima ou do produto nas fases de processamento ou mesmo quando acabado (SANTOS, 2007, AKOACHERE et al., 2018). A Escherichia coli distribui-se a partir das fezes, habitat específico ou primário, alcançando o solo e sendo veiculada principalmente pela água até (AMÂNCIO et al., 2003).

A Salmonella é outro gênero de grande relevância como patógeno veiculado por alimentos pertencente à Família Enterobacteriaceae. O principal reservatório desta bactéria é o trato gastrintestinal do homem e de animais, principalmente aves e suínos. Apesar da principal fonte de transmissão de Salmonella serem os alimentos de origem animal, vários estudos realizados com produtos de origem vegetal detectaram a presença desta bactéria (SANTOS, 2007, SANTOS et al., 2012; ONUORAH et al., 2016 ).

Para garantir a segurança dos alimentos, o Ministério da Saúde estabeleceu padrões microbiológicos sanitários para alimentos, por meio da Resolução RDC N012, de 2 de janeiro de 2001, não existindo padrões específicos para os frutos minimamente processados. Porém, estes podem ser inseridos no grupo de alimentos designados como: "frutas frescas, in natura, preparadas (descascadas ou selecionadas ou fracionadas), sanificadas, refrigeradas ou congeladas, para consumo direto". Segundo tais padrões, hortaliças cruas não devem apresentar Salmonella spp em $25 \mathrm{~g}$ de produto e para Coliformes a $45^{\circ} \mathrm{C}$ a tolerância para amostra indicativa é de $10^{2}$ de número mais provável $\left(\mathrm{NMP} \mathrm{g}^{-1}\right)$ (BRASIL, 2001).

No Brasil, pesquisas têm sido conduzidas para verificar a qualidade microbiológica das hortaliças que são ingeridas in natura. Dentre os micro-organismos pesquisados, os coliformes termotolerantes são frequentemente encontrados e evidenciam a relevância deste problema pelo elevado número destes micro-organismos em amostras de alimentos (TAKAYANAGUI et al., 2001; RIBEIRO et al., 2005, SANTOS et al., 2016). 
Nas hortaliças minimamente processadas o cenário não é diferente. Trabalhos realizados indicam a contaminação por micro-organismos patogênicos. Pinheiro et al. (2005), analisaram 100 amostras de frutas minimamente processadas, e verificaram que as amostras apresentavam Salmonella ssp e coliformes fecais. Santos et al. (2010), analisaram 155 amostras de hortaliças minimamente processadas encontrando em $29 \%$ coliformes fecais acima do limite permitido pela legislação. No presente trabalho objetivou-se avaliar a qualidade microbiológica de amostras de cenouras minimamente processadas e cenouras in natura, comercializadas no Município de Fernandópolis-SP.

\section{MATERIAL E MÉTODO}

Foram analisadas, em triplicata, 30 amostras de cenouras minimamente processadas e 30 amostras de cenouras in natura, adquiridas em comércios do Município de Fernandópolis, SP. Foi estabelecido como unidade amostral um pacote de $200 \mathrm{~g}$ para cenouras minimamente processadas e $200 \mathrm{~g}$ para cenouras a granel (in natura), colhidas aleatoriamente, entre as que se encontravam à disposição do consumidor. As amostras provenientes dos pontos de comercialização foram acondicionadas, individualmente em caixas isotérmicas contendo gelo e transportadas para análise microbiológica.

As análises microbiológicas foram realizadas de acordo com Silva et al. (2010). Para tal, 25 gramas de amostra de cenoura foram pesados e homogeneizados em $225 \mathrm{~mL}$ de água peptonada tamponada $(0,1 \%)$. A partir desta diluição inicial de $10^{-1}$, foram preparadas várias diluições decimais, utilizando-se o mesmo diluente.

Para a determinação de coliformes totais e coliformes termotolerantes, $1 \mathrm{~mL}$ de cada diluição foi inoculada em tubos contendo caldo lauril sulfato (Oxoid ${ }^{\circledR}$ ) com um tubo de Durham invertido, em série de três tubos por diluição. Os tubos foram incubados a $35^{\circ} \mathrm{C}$, por $24-48$ horas. Nos inóculos positivos foi observada a produção de gás no tubo de Durham. A seguir, três alçadas de cada tubo positivo foram repicadas em tubos de ensaio contendo caldo E.C. (Escherichia coli, Oxoid $^{\circledR}$ ), para a confirmação de coliformes termotolerantes (CT), incubados a $45^{\circ} \mathrm{C}$, por $24-48$ horas. Após o período de incubação, foi realizada a leitura pela observação da presença de gás no tubo de Durham invertido. Dos tubos positivos foram retiradas alíquotas de $0,1 \mathrm{~mL}$ e semeadas em placas de Petri contendo meio ágar Eosina Azul de Metileno (Oxoid $\left.{ }^{\circledR}\right)$ (EMB) para confirmação de Escherichia coli.

Para pesquisa de Salmonella spp as amostras contida na água salina peptonada foi incubada a $37^{\circ} \mathrm{C} / 24$ horas. Estas amostras foram transferidas para dois diferentes caldos de enriquecimento seletivo, Rappaport-Vassiliadis $\left(\right.$ DIFCO $\left.^{\circledR}\right)$ e Tetrationato-Novobiocina (DIFCO ${ }^{\circledR}$ ), incubados a 37 e $42^{\circ} \mathrm{C}$ por 24 horas. Cada amostra foi semeada em placas de Petri com Ágar Verde Brilhante 
$\left(\right.$ Oxoid $\left.^{\circledR}\right)$ e em Ágar Hektoen $\left(\right.$ Oxoid $\left.^{\circledR}\right)$, e incubadas por 24 horas a $37^{\circ} \mathrm{C}$. As colônias típicas obtidas nas placas foram confirmadas pelas provas bioquímicas de descarboxilação da lisina, fermentação da lactose e/ou sacarose e produção de $\mathrm{H}_{2} \mathrm{~S}$, no Ágar Lisina Ferro (DIFCO) e Ágar Tríplice Açúcar Ferro (DIFCO).

Os dados obtidos foram tabulados para obtenção das médias e da porcentagem de contaminação, sendo os resultados expressos em UFC $\mathrm{g}^{-1}$.

\section{RESULTADO E DISCUSSÃO}

As cenouras minimamente processadas e in natura apresentaram coliformes totais e coliformes termotolerantes com confirmação de Escherichia coli em $20 \%$ e $100 \%$ das amostras, respectivamente. (Figura 1). Estes organismos podem ter sido introduzidos nas cenouras durante o crescimento, colheita, manipulação, armazenamento e distribuição (ONUORAH et al, 2016; AKOACHERE et al., 2018). A enumeração de coliformes totais é utilizada para avaliar as condições higiênicas do produto, pois, quando em alto número, indica contaminação decorrente de falha durante o processamento, limpeza inadequada ou tratamento térmico insuficiente. Já a detecção de elevado número de bactérias do grupo dos coliformes fecais em alimentos é interpretada como indicativo da presença de patógenos intestinais, visto que a população deste grupo é constituída de alta proporção de Escherichia coli (SILVA et al., 2010, TORTORA et al., 2012, SANTOS et al., 2012).

O grupo dos coliformes termotolerante é considerado o principal agente causador de contaminação associado à deterioração de alimentos, causando fermentações anormais e estufamento precoce dos produtos (ALMEIDA; FRANCO, 2003). Estes micro-organismos são destruídos pela temperatura de pasteurização e, em alimentos processados é considerada uma indicação útil de contaminação pós-sanitização ou pós-processo, evidenciando práticas de higiene e sanitização aquém dos padrões requeridos para o processamento de alimentos (SILVA et al., 2010).

Presença de Salmonella spp foi observada unicamente nas amostras de cenouras comercializadas in natura. Verificou-se que 28 amostras $(93,3 \%)$ apresentaram contaminação por esta bactéria (Figuras 1 e 2). De acordo com a legislação vigente (BRASIL, 2001), o gênero Salmonella deve estar ausente nos alimentos, devido a sua capacidade de disseminação, pode ser isolada de diferentes fontes como consequência de práticas inadequadas de manipulação e sanitização (AKOACHERE et al., 2018). 
Figura 1: Porcentagem de coliformes totais, coliformes fecais, Escherichia coli e Salmella spp isolados de cenouras minimamente processadas e cenouras in natura.

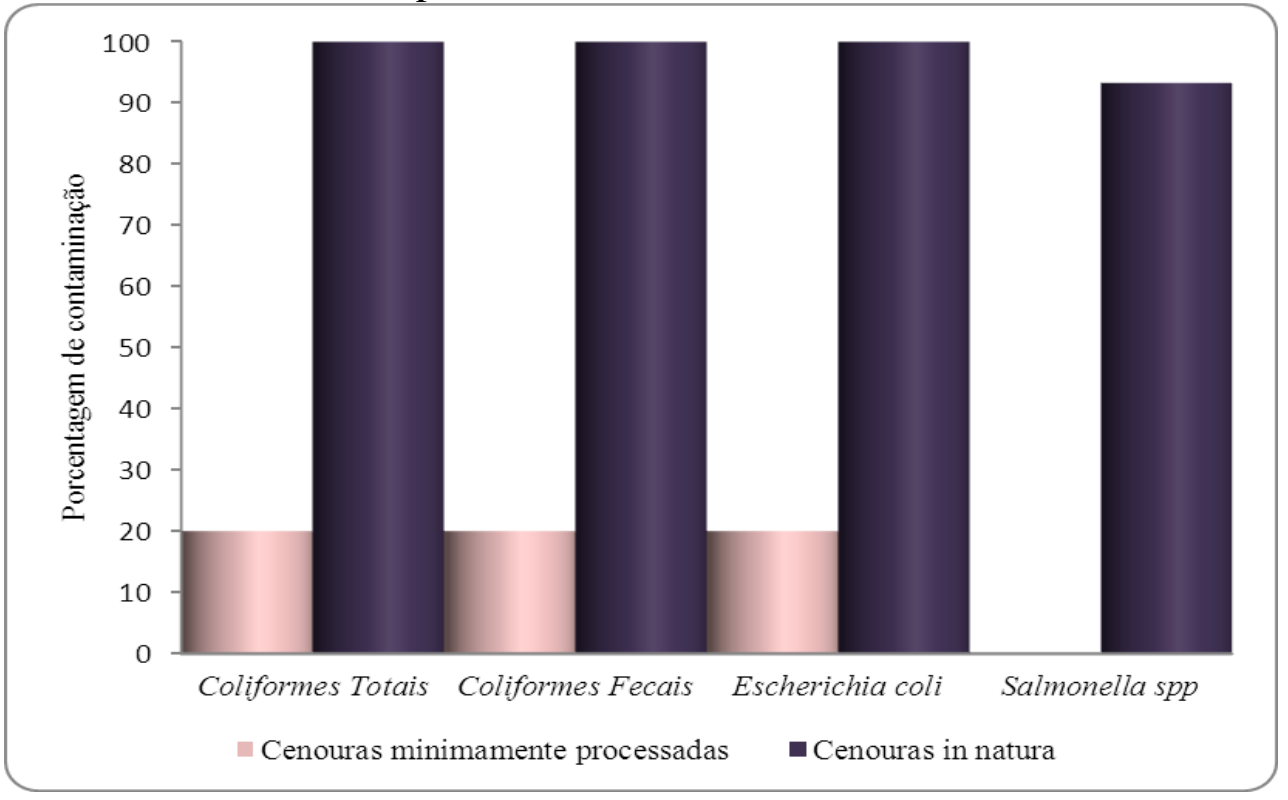

Fonte: Dados da pesquisa 2017.

Figura 2- Colônias de Salmonella spp em Ágar Hektoen, isoladas de amostras de cenouras in natura.

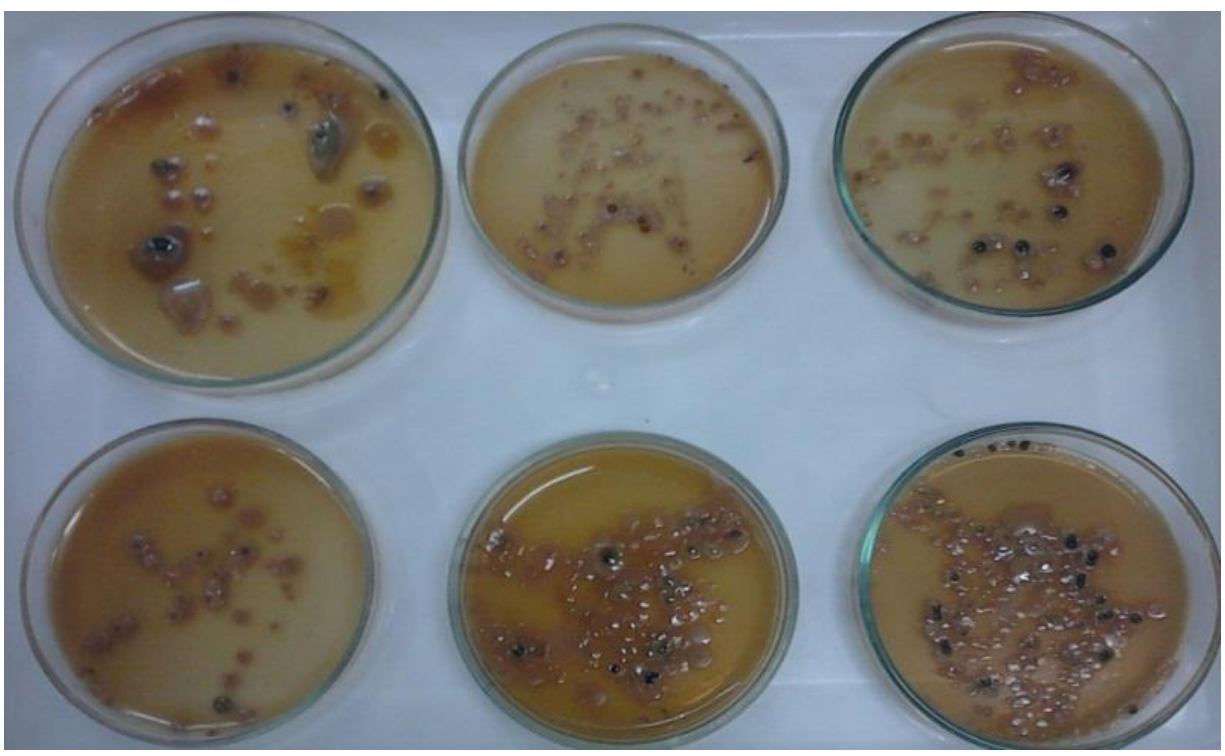

Fonte: Dados da pesquisa 2017.

$\mathrm{Na}$ tabela 1 estão apresentados os resultados contagens de coliformes totais, coliformes termotolerantes, Escherichia coli, Salmonella spp isolados de cenouras minimamente processadas e cenouras in natura. Constatou-se que a concentração de coliformes totais, coliformes termotolerantes e E.coli variou entre $10^{3}$ e $10^{9}$ UFC g-1. O número de coliformes acima de $1,0 \times 10^{3}$ UFC $\mathrm{g}^{-1}$ (Tabela 1) é indicativo de deficiências de higiene na produção, sendo os coliformes considerados indicadores de contaminação do ambiente e resíduos de fezes (BRITO et al., 2002). Segundo Santos et al. (2012), populações de E. coli, muitas vezes são avaliadas para 
monitorar a condição sanitária dos alimentos e como um indicador de contaminação de origem fecal

Tabela 1: Média e porcentagens das contagens de coliformes totais, coliformes termotolerantes, Escherichia coli e Salmonella spp isolados de cenouras minimamente processadas e cenouras in natura.

\begin{tabular}{lccc|ccc}
\hline \multirow{2}{*}{ Micro-organismos } & \multicolumn{3}{c|}{$\begin{array}{c}\text { Cenouras minimamente } \\
\text { processadas }\end{array}$} & \multicolumn{3}{c}{ Cenouras in natura } \\
\cline { 2 - 7 } & $\mathbf{U F C ~ g}^{\mathbf{- 1}}$ & $\begin{array}{c}\mathbf{N}^{\mathbf{0}} \text { de } \\
\text { Amostras }\end{array}$ & $\%$ & $\mathbf{U F C ~ g}^{-1}$ & $\begin{array}{c}\mathbf{N}^{\mathbf{0}} \text { de } \\
\text { Amostras }\end{array}$ & $\%$ \\
\hline Coliformes Totais & $3,2 \times 10^{6}$ & 4 & 13,3 & $1,1 \times 10^{9}$ & 9 & 30,0 \\
& $1,2 \times 10^{4}$ & 2 & 6,7 & $1,9 \times 10^{4}$ & 11 & 36,7 \\
Coliformes & - & - & - & $6.2 \times 10^{3}$ & 10 & 33,3 \\
Termotolerantes & $1,5 \times 10^{6}$ & 4 & 13,3 & $1,2 \times 10^{6}$ & 9 & 30,0 \\
Escherichia coli & $1,0 \times 10^{3}$ & 2 & 6,7 & $1,9 \times 10^{3}$ & 21 & 70,0 \\
& $1,5 \times 10^{6}$ & 4 & 13,3 & $2,4 \times 10^{4}$ & 8 & 26,7 \\
Salmonella spp & $1 \times 10^{3}$ & 2 & 6,7 & $1,5 \times 10^{3}$ & 22 & 73,3 \\
\hline
\end{tabular}

Fonte: Dados da pesquisa 2017.

As cenouras, sendo uma cultura de raiz, poderiam ter recebido contaminação do solo, água de irrigação, resíduos de animais usados como fertilizantes, água usada para lavagem e de manipuladores. A superfície, irregular da raiz retem a sujeira contendo organismos que não podem ser facilmente removidos por lavagem leve (FRANZ et al., 2010). Observou-se alta contaminação em cenouras in natura por coliformes termotolerantes com confirmação Escherichia coli (Tabela 1). A legislação brasileira por meio da RDC $\mathrm{n}^{0} 12$ de janeiro de 2001 estabelece os limites microbiológicos para coliformes e para Salmonella em hortaliças, in natura, podendo apresentar $10^{2} \mathrm{NMP} \mathrm{g}^{-1}$ de coliformes e ausência de Salmonella, Estariam de acordo com esta regulamentação $80 \%$ das cenouras minimamente, enquanto que as $100 \%$ da cenouras in natura estavam fora dos padrões exigidos pela legislação (Tabela 1).

Nos produtos minimamente processados existe risco de contaminação devido aos cortes da casca, e da disponibilidade de nutrientes provenientes do dano exercido nas células durante o preparo, assim como a manipulação originam o aumento da possibilidade de contaminação por micro-organismos patogênicos (AGUILA et al., 2006).

O controle destes micro-organismos é obtido pela sanitização, que desempenha um papel importante na qualidade dos produtos minimamente processados, aumentando assim o tempo de prateleira (OLIVEIRA; VALLE, 2000). 
A elevada carga microbiana encontrada nas cenouras in natura (tabela 1) evidenciou que a contaminação por micro-organismos potencialmente patogênicos pode ter sido decorrente de procedimentos inadequados na condução da cultura, na colheita, manipulação, no armazenamento e na distribuição. A presença destes micro-organismos é um risco a saúde pública devido às doenças causadas por os mesmos (VIEIRA et al., 2008). Por tanto, é imperativo que práticas higiênicas adequadas sejam colocadas em prática durante o armazenamento e manuseio das cenouras. Segundo Onuorah et al. (2016), a redução na taxa de deterioração das cenouras pode ser obtida pela observação de boas práticas agrícolas. Isso inclue a proteção de águas superficiais e subterrâneas, utilização do esterco adequadamente tratado, enquanto as instalações de colheita e de armazenamento devem ser limpas e desinfetadas antes da safra. Além disso, recipientes limpos devem ser usados para o transporte de cenouras frescas e sujeiras e a lama aderente deve ser removida.

\section{CONCLUSÃO}

De acordo com a metodologia empregada e pelos resultados obtidos pode concluir-se que: - as cenoras minimamente processadas $(20 \%)$ e as cenouras in natura $(100 \%)$ apresentaram contaminação por coliformes totais, coliformes termotolerantes e Escherichia coli;

- as cenouras in natura $(93,3 \%)$ estavam contaminadas por Salmonella spp;

- a carga microbiana variou ente $10^{3}$ e $10^{9} \mathrm{UFC} \mathrm{g}^{-1}$ de cenoura.

\section{REFERÊNCIAS}

AGUILA, J.S; SASAKI, F.F.; HEIFFIG, L.S.; ONGARELLI, M.G.; GALLO, C.R; JACOMIMO,A.P. et al. Determinação da microflora em rabanetes minimamente processados. Horticultura Brasileira, v. 24, n. 1, p.75-78, 2006.

AKOACHERE, J.F.T.K.; TATSINKOUF, B.; NKENGFACK, J.F. Bacterial and parasitic contaminants of salad vegetables sold in markets in Fako Division, Cameroon and evaluation of hygiene and handling practices of vendorsl. BMC Research Notes, v.11, n.100, p. 1-7, 2018. Doi: 10.1186/s13104-018-3175-2

ALMEIDA, P.M.P.; FRANCO, R.M. Avaliação bacteriológica de queijos tipo Minas Frescal com pesquisa de patógenos importantes à saúde pública: Staphylococcus aureus, Salmonellasp. e Coliformes fecais. Higiene Alimentar, v.17, n.111, p.79, 2003

ALVES, J.A.; VILAS BOAS, E.V.B.; VILAS BOAS, B.M.; SOUZA, E.C. Qualidade de produto minimamente processado à base de abóbora, cenoura, chuchu e mandioquinha-salsa. Ciência $\mathbf{e}$ Tecnologia de Alimentos, v. 30, n. 3, p. 625-634, 2010. 
AMÂNCIO, G, C.; PEREIRA, M. L.; CARVALHO, E. P. Escherichia coli Enterohemorrágica (E. coli O157: H7). 1 - Algumas considerações epidemiológicas sobre ecossistema, patogênese e controle. Boletim da Sociedade Brasileira de Ciência e Tecnologia de Alimentos, v. 37, p. 6573, 2003.

ANDRADE, N.; BASTOS, M. S. R.; ANTUNES, M. A Higiene e sanitização de frutas e hortaliças minimamente processadas. In: MORETTI, C. L. (Ed.). Processamento mínimo de frutas e hortaliças. Brasília, DF: Embrapa Informação Tecnológica, 2004.

BRASIL. Resolução $\mathrm{n}^{\circ}$ 12, de 02 de janeiro de 2001.Regulamento técnico sobre os padrões microbiológicospara alimentos. Diário Oficial [da] República Federativa do Brasil, Brasília, DF, 10 jan. 2001.p. 1-54.

FANTUZZI, E.; PUSCHMANN, R.; VANETTI, M. C. D. Microbiota contaminante em repolho minimamente processado. Ciência e Tecnologia de Alimentos, v. 24, n. 2, 2004 .

FRANCO, B. D. G. M; LANDGRAF, M. Microrganismos patogênicos de importância em alimentos. Microbiologia dos alimentos. São Paulo, Atheneu, 1996, p.50-60.

FRANZ, E.; TROMP, S.O.; RIJGERSBERG, H.; VAN DER FELS-KLERX, H.J. Quantitative microbial risk assessment for Escherichia coli O157:H7, Salmonella, and Listeria monocytogenes in leafy green vegetables consumed at salad bars. Journal of Food Protection, v.73, n.2, p.274$285,2010$.

LIMA, K.S.C.; LIMA,L.S; ROSA,H.L.;GODOY,R.L.;SABAA-SRUR,A.U.O. Cenouras minimamente processadas em embalagens com atmosferas modificadas e tratadas com radiação gama: avaliação microbiológica, físico-química e química. Ciência e Tecnologia de Alimentos, v. 23, n. 2. 2003.

OLIVEIRA, E.C.M.; VALLE, R.H.P.D. Aspectos microbiológicos dos produtos hortícolas minimamente processados. Higiene Alimentar, v. 14, p. 50-54, 2000.

ONUORAH, S.; NRIAGU, O.; OBIKA, I. Isolation, Characterization and dentification of microorganisms from spoilt carrots obtained from Ose Market Onitsha, Nigeria. Universal Journal of Biomedical Engineering, v. 4, n.1, p.6-9, 2016. doi: 10.13189/ujbe.2016.040102

PINHEIRO, N. M.S.; FIGUEIREDO, E.A.T de; FIGUEIREDO, R.W.de; MAIA, G.A.;SOUZA, P.H. de;. Avaliação da qualidade microbiológica de frutos minimamente processados comercializados em supermercados de Fortaleza. Revista Brasileira de Fruticultura, v. 27, n. 1, p.153-156, 2005 .

RIBEIRO, Á.; GUERRA, R. M. S. N. C.; COSTA, F. N.; ALVES, L. M. C. Avaliação das condições higiênico-sanitárias de alfaces e águas de irrigação de hortas da Ilha de São Luís - Ma. Revista de Higiene Alimentar, v. 19, n. 130, p.20-23, 2005.

SANTOS, Y.T.O. Qualidade sanitária de hortaliças cultivadas em um distrito sanitário de Salvador- BA e eficiência de soluções antimicrobianas sobre linhagens de Escherichia coli. Salvador. UFBA, 2007. (Dissertação de mestrado), 85p.

SANTOS, T.B.A.dos. Micorganismos indicadores em frutas e hortaliças minimamente processadas. Ciência e Tecnologia de Alimentos, v. 13, n. 2, p. 141-146, 2010. 
SANTOS, M.I.; CAVACO, A.; GOUVEIA, J.; NOVAIS, M.R.; NOGUEIRA, P.J.; PEDROSO, L. et al. Evaluation of minimally processed salads commercialized in Portugal. Food Control, v.23, n. 1, p.275-281, 2012.

SILVA, N. da; JUNQUEIRA, V.C.A; SILVEIRA, N. F.A. Manual de Métodos de Análise Microbiológica de Alimentos, Livraria Varela, São Paulo, 295p., 2010.

TAKAYANAGUI, O. M. Fiscalização de verduras comercializadas no município de Ribeirão Preto, SP. Revista da Sociedade Brasileira de Medicina Tropical, v. 34, n. 1, p. 37-41, 2001.

TEMGOUA, E.; NTANGMO, T.H.; NJINE.,T. Vegetable production systems of swamp Zone in Urban Environment in West Cameroon: case of Dschang City. Universal Journal of Environmental Research and Technology, v.2, n.2, p.83-92, 2015.

TORTORA, G.J., FUNKE, B.R., CASE, C.L. Micro-organismos e doenças humanas. Microbiologia, Artmed, Rio Grande do Sul: Artmed, 2012. p.584-765.

VIEIRA, R. H. S. F. Microbiologia, higiene e qualidade do pescado. São Paulo: Livraria Varela, 2008. 380 p. 